\title{
Causes and Characteristics of Professional Mobility for Teachers in Morocco Case of Secondary School Teachers Who have Chosen to Become Educational Guidance Counselors
}

\author{
${ }^{1}$ AbderrazakFaiq, ${ }^{1}$ Brahim Darraj, ${ }^{2}$ Azzeddine Atibi, ${ }^{1}$ Mohamed Radid \\ ${ }^{1}$ Laboratoire de Chimie Physique des Matériaux \\ Faculté des Sciences Ben M'sik \\ Université Hassan II de Casablanca \\ Morroco \\ ${ }^{2}$ Centre Régional des Métiers d'éducation et de formation \\ CRMEF Casablanca-Settat \\ Abderrazak.faiq@gmail.com
}

\begin{abstract}
When it comes to changing one's profession after a several years of professional experience in a given field, It must be admitted that the person who adopts this approach is very persevering in the quest for self-realization. Thus, the search for improvement of the working environment and its conditions are often behind this type of choice. To try to understand this phenomenon of professional mobility, we conducted a study that concerning 1st cycle secondary school teachers who became guidance counselors and we focus on two parameters concerning this population: the causes that led them make this choice, and their socio-cultural characteristics (entry profiles). This information was collected via a questionary administered to all active guidance counselors. The results of this research led us to conclude a review of the flow of national education staff and to highlight the lack of professionals for certain subjects taught.
\end{abstract}

Keywords: Professional Mobility, Working Conditions, Secondary School Teacher, Guidance Counselor, Administrative and Financial Situation, Grade

Received: 1 March 2019, Revised 1 June 2019, Accepted 9 June 2019s

DOI: $10.6025 /$ jet/2019/10/3/100-104

C2019 DLINE. All rights reserved

\section{Introduction}

Nowadays, new jobs are being created, as is the destruction of some others. In companies, the factors of technological and organizational evolution are at the origin of searching for flexibility signifying a capacity of adaptation to the evolutions of the professional environment and a certain conformism towards the requirements of development of skills or of regular changes. This new situation, which is often worrying for employees, is further complicated by other factors such as the relationship with customers, deadlines, commercial objectives, new process, working conditions (1)... The field of education is not far from this so embarrassing situation, we are therefore faced with multiple problems that hinder the action of teachers, which leads them to see their jobs differently (2).

In this study, we will focus on teachers of junior high school, said the college, who decided to change their profession to become

$100 \quad$ Journal of E-Technology Volume 10 Number 3 August 2019


guidance counselors in the same Ministry of Education. And we would try to know this population and understand what pushes them to adopt this professional mobility.

"In the context of a society where institutional frameworks are relatively weak, the professional and/or personal transitions constitute privileged moments of deliberation on the meaning of our existential commitments". (3)

Indeed, the secondary school teacher in Morocco is a specialist. He teaches only one subject or group of subjects. His main mission in college is to transmit knowledge and know-how in its discipline, to educate students, to contribute to their education and prepare them for citizenship. He is also called upon to guide them, to help them organize themselves in their personal work and to evaluate the acquired knowledge (4). To become a teacher of the college, you must have a license (bac +3 ) relative to the subject that you plan to teach and pass the competition in regional centers of trades education and training CRMEF for a year. It should be noted that before the reform of the teacher training system in Morocco in 2011, becoming a secondary school teacher requires to succeed two years of training at the CPR (regional pedagogical center) open to bachelors on competition. Concerning its administrative situation, the teacher of the 1st cycle in secondary school is classified in the 2nd grade (scale 10) and he has the possibility of promotion in 1st grade (scale11) and not in the main grade: the off scale.

On the other hand, the guidance counselor is an employee of the National Education, and ex secondary school teacher, he listens, informs and advises young people and their parents on educational or vocational guidance (5). He can work in an individual interview or in a group session at the Provincial Information and Guidance Center (CPIAO) or in a school district (set of schools geographically close to each other). The main objective of these interviews is to help young people and their parents to have an idea about his school situation and his personal and professional project. The guidance counselor is a former secondary school teacher who has at least 4 years of experience as a teacher and who was able to pass the written and oral tests of the competition in front of a jury of the center for orientation and planning of education (COPE) located in Rabat, which is the only center in the field of guidance in the African region. Concerning his administrative situation the guidance counselor is classified from the $2 \mathrm{nd}$ grade (scale10) and can progress to the 1st grade (scale11) as he can benefit from the main grade: the out of scale.

After describing the context in which these two professionals of education are working, we will try to approach the determinants of the phenomenon of professional mobility among former college teachers who have become guidance counselors. So our goals will be spread over two dimensions:

- Determine the characteristics of college teachers (their entry profiles) who opted for the choice to become guidance counselors.

- Identify the main causes behind this vocational choice among college professors to become guidance counselors.

\section{Methodology}

As a reminder, the purpose of this research is to answer the question: "What are the characteristics and causes that pushed some secondary school teachers in Morocco to proceed to this professional mobility to become guidance counselors?"

In this chapter will be described the method adopted to achieve this goal, that is to say to highlight the determinants of the phenomenon of professional mobility in Morocco. Thus, to begin, details will be given on the type of research adopted, the target population and the approach for data collection and analysis.

\subsection{Type of Research}

The present research is intended to determine the characteristics and causes for which certain teachers of the college cycle in Morocco have made this professional mobility to become guidance counselors.

The point of view adopted here considers that the reality of these determinants is global and independent of the researcher's vision, which prompted us to adopt a positivist, predominantly qualitative approach since the intention is to produce global information about this reality reduced here to two parameters: the socio-cultural characteristics of teachers and the causes that led them change their job.

\subsection{Target Population}

Journal of E-Technology Volume 10 Number 3 August 2019 
During this research, the target population comes down to the set of guidance counselors in Morocco, which could be contacted via the electronic virtual space "yahoo-groups" dedicated to the mutual exchange between managers of the guidance and those of educational planning.

\subsection{The Data Collection Tool}

The instrument adopted during this research is a questionnaire of 19 items listed under two headings: characteristics and profiles of the interviewees and then a second part dedicated to the causes and determinants of the phenomenon. This quetionnary was administrated via Internet by e-mail addressed to all guidance counselors and inspectors, who have been themselves former advisers. It was developed from the "google form" functionality which allows having a detailed and well-ordered statistical and graphical interface.

\section{Results}

From the google form functionality we had a global view of all the answers to the questionnaire items. Once the questionnaires were completed, a recount was conducted and the data was coded and automatically grouped into an Excel database. This made it possible to present the usual descriptive statistics for each of the variables. The main results can be summarized as follows:

\section{Socio Professional Characteristics and Profiles of the Respondents}

\begin{tabular}{|l|c|c|}
\hline Male & 9 & $96.8 \%$ \\
\hline Female & 3 & $3.2 \%$ \\
\hline
\end{tabular}

Figure 1. Distribution of respondents by gender

Among those surveyed, "Figure 1" of whom there are 93 career counselors, there are only three women who participated in the survey (about 3\%).

It should be noted that the age range of the surveyed population is from 33 to 58 years old. The under 40 s currently are in number of $57 / 93$ which is $61.29 \%$.

\begin{tabular}{|l|c|l|}
\hline Scientist & 51 & $54.8 \%$ \\
\hline Literary & 15 & $16.1 \%$ \\
\hline Technical & 27 & $29 \%$ \\
\hline Other & 0 & $0 \%$ \\
\hline
\end{tabular}

Figure 2. Classification of respondents by type of academic training

According to "Figure 2", more than half of the respondents hold a scientific baccalaureate (55\%), and almost 1/3 are from technical bac (29\%), while holders of a literary baccalaureate are a minority representing $1 / 6$ (almost 16\%).

\begin{tabular}{lcc}
\hline I went directly to the CPR & 42 & $45.2 \%$ \\
\hline I had passed my first year in higher education & 9 & $9.7 \%$ \\
\hline I had passed my DEUG & 30 & $32.3 \%$ \\
\hline I had passed my LICENSE (bac +3 ) & 0 & $0 \%$ \\
\hline I had passed my LICENSE (bac +4$)$ & 9 & $9.7 \%$ \\
\hline I had a bac +5 or more & 3 & $3.2 \%$ \\
\hline
\end{tabular}

Figure 3. Distribution of respondents by university level

102 Journal of E-Technology Volume 10 Number 3 August 2019


This figure shows us that almost half of the respondents (45\%) accessed the CPR directly, while one-third (32\%) had a bac +2 and $1 / 10$ had a bac $+4(9.7 \%)$. three of these respondents had a bac +5 or higher.

\begin{tabular}{lll}
\hline Arabic & 0 & $0 \%$ \\
\hline French & 15 & $16.1 \%$ \\
\hline English & 0 & $0 \%$ \\
\hline Islamic education & 0 & $0 \%$ \\
\hline History and Geography & 3 & $3.2 \%$ \\
\hline Mathematics & 24 & $25.8 \%$ \\
\hline Physics / Chemistry & 3 & $3.2 \%$ \\
\hline Life and earth sciences & 6 & $6.5 \%$ \\
\hline Technology & 24 & $25.8 \%$ \\
\hline Physical education and sport & 12 & $12.9 \%$ \\
\hline data processing & 3 & $3.2 \%$ \\
\hline Music Education & 0 & $0 \%$ \\
\hline Family Education & 3 & $3.2 \%$ \\
\hline Other & 0 & $0 \%$
\end{tabular}

Figure 4. Distribution of respondents by teaching discipline

According to this table "Figure .4", we note that the dominant specialty of teachers was shared equally by the mathematics (26\%) and technology (26\%) teachers, who together accounted for more than half of the respondents $(52 \%)$. They are followed by those of French $(16,1 \%)$ then those of the EPS $(12,9 \%)$, then the teachers of SVT $(6,5 \%)$ and at the end the subjects history / geography, physics / chemistry, computer and family education are represented by three teachers each (3.2\%).

\section{Causes and Determinants of the Vocational Choice of Changing Profession}

\begin{tabular}{lll}
\hline Promote my financial situation (from scale 9 to scale10) & 72 & $77.4 \%$ \\
\hline I felt that my skills would be better deployed in this job & 48 & $51.6 \%$ \\
\hline The need to still feel able to pursue higher education & 45 & $48.4 \%$ \\
\hline Attracted by the training content at COPE & 39 & $41.9 \%$ \\
\hline I can not stand the classroom conditions anymore & 27 & $29 \%$ \\
\hline My health no longer allows me to work in class & 6 & $6.5 \%$ \\
\hline Simply change the frame & 30 & $32.3 \%$ \\
\hline Others & 15 & $16.1 \%$ \\
\hline
\end{tabular}

Figure 5. Distribution of respondents according to their causes of adoption of change of occupation choices

During this questionnary item which is related to "Fig. 5 ", the respondents had the possibility to choose several answers and that is why all the percentages are greater than $100 \%$. We find that the majority of respondents (77.4\%) opted to become a guidance counselor on the pretext of promoting their financial situation and thus benefit from the possibility of further promotion to grade outside the scale.

Secondly, almost half of the respondents believe that the causes are of the order of self-realization, namely the feeling that their skills would be better deployed in this profession or the need to feel themselves still capable of pursuing higher education.

On the other hand, the general trend states that almost $1 / 3$ of respondents (between $29 \%$ and $32 \%$ ) announce that the third reason is of the order of the working conditions in class which they consider uncomfortable and besides they prefer to change the setting.

\begin{tabular}{|c|c|c|}
\hline Yes & 54 & $58.1 \%$ \\
\hline No & 39 & $41.9 \%$ \\
\hline
\end{tabular}

Figure 6. Remake a change of profession 
By asking the respondents if they had the opportunity to change their job again, will they do so? according to "fig; 6 ", the answer was that half of the respondents (58\%) expressed their predisposition to repeat this professional mobility a second time.

The main causes for this possible second occupational mobility are:

- Of all the pretexts proposed by the guidance counselors resulting from the survey, those who deplore the working conditions $(25 \%)$ are in number of 24

- For self-realization, the number of respondents is estimated at 18/93 (19\%);

- A proportion of the respondents (13\%) maintain the cause of financial promotion (12/93);

- The rest (39/93) would do it for other reasons if necessary (41\%).

\section{Analysis and Discussion}

The main result of this research is a review of the flow made by secondary school teachers of scientific or technical disciplines who migrate to orientation thus creating a huge need for human resources with the Ministry of National Education who has been forced to use contract teachers to fill this gap. In addition, this migrant population is very young (the under-40s represent more than $60 \%$ ) which maintains this spirit of continuous training even in an extra-professional setting.

When asked about causes that led them to make this choice of changing of profession, the majority of respondents (more than $75 \%$ ) said that the promotion of their financial situation is the first reason they opted for this professional mobility; it is indeed a question of soliciting a better remuneration of wages and to insure in the medium or long term a financial peace by promotion to the higher rank: the out-scale. In this same population, we find that $50 \%$ of respondents believe that they have used this professional mobility for a second reason which is self-realization: some hoped to better deploy their skills in this new job, others needed to feel still able to pursue higher education. Finally, about $30 \%$ of respondents deplore as the third cause the unfavorable conditions of work as a teacher in class: it is to seek his comfort zone to better carry out his job.

Finally, we do not claim to have identified all aspects of the phenomenon, but we believe that it is a micro research that can open the debate by other studies.

\section{Bibliography}

[1] Van Schingen, É., Ladegaillerie, G., Lefebvre, H., Challier, MP., Rothan-Tondeur, M. (2015). The professional mobility of hospital nurses. Soins. 2015 Sep14; (798): 25-30. doi: 10.1016/j.soin.2015.07.012.

[2] Xavière, L., Thérèse, P. R. (2014). Professional transitions associated with the integration of novice teachers: the impact of professionalization contexts and interpersonal dynamics. OSP [Online] ,43/4 | 2014, Online since 15 December 2017, connection on 22 september 2018. URL: http://journals.openedition.org/osp/4488 ; DOI : 10.4000/osp.4488

[3] Jean-Luc Mand Alain B-B. (2001). Identity Dynamics and Self-Representations in a Personal and Professional Transition Phase. Connexions, 2001 february, (76) : 15-28. doi.org/10.3917/cnx.076.0015

[4] Patrick, R., Jean-Pierre, V. (2017). Becoming a teacher today: Increasing uncertainties? », Revue internationaled'éducation de Sèvres [Online], 74 | 2017, Online since 01 April 2017, connection on 25 October 2018. URL: http://journals.openedition.org/ries/ 5777

[5] Dominique, M., and Jean-Jacques, R. (2014). Social Bond and Desire in the Quest for Vocational Guidance Travailler, 2014 feb $16,(32): 131-150$. 